\title{
NO kidding: exhaled nitric oxide fraction in preschool children
}

\author{
Mariëlle W. Pijnenburg ${ }^{1}$ and Peter J. Merkus ${ }^{2}$
}

Affiliations: ${ }^{1}$ Dept of Paediatrics/Paediatric Respiratory Medicine, Erasmus Medical Centre - Sophia Children's Hospital, Rotterdam, The Netherlands. ${ }^{2}$ Dept of Pediatrics, Division of Respiratory Medicine and Allergology, Amalia Children's Hospital Radboud University Medical Centre, Nijmegen, The Netherlands.

Correspondence: Mariëlle W. Pijnenburg, Dept of Paediatrics/Paediatric Respiratory Medicine, Erasmus Medical Centre - Sophia Children's Hospital, PO Box 2060, 3000 CB, Rotterdam, The Netherlands.

E-mail: m.pijnenburgderasmusmc.nl

0

@ERSpublications

FeNO may be helpful in predicting future asthma in preschool wheezing children, but more longitudinal data are needed http://ow.ly/DXKxR

Wheeze is one of the most prevalent symptoms in preschool children with huge impacts on children and their families, on healthcare utilisation and hence costs [1]. While most children will become asymptomatic by 5-6 years of age, some will develop asthma or, even more importantly, severe problematic asthma and/or will experience an accelerated decline in lung function. Several studies have shown that lung function in asthmatic children at 6 years of age is already reduced compared with nonasthmatic children, in particular among children with allergic asthma [2]. This impaired lung function seems to be present soon after birth in children who are at risk of asthma [3]. Hence, the preschool years and the prenatal period seem of the utmost importance if we are looking for a window of opportunity to prevent asthma or to identify those children who are at risk for severe disease.

To date, prediction of which wheezy toddler will go on to develop asthma with absolute certainty is not possible. Asthma prediction rules have been hampered by low positive predictive values and objective measurements like lung function tests are not feasible in preschool children in routine daily care. However, eczema, a positive family history for asthma or allergic diseases and the presence of specific IgE to aeroallergens are important risk factors for later development of asthma [4].

For two decades nitric oxide in exhaled air (fraction of exhaled nitric oxide (FeNO) has been used as a biomarker reflecting eosinophilic airways inflammation [5]. Along with exhaled $\mathrm{CO}_{2}$, exhaled $\mathrm{NO}$ is the only biomarker that has made it from bench to bedside. Handheld analysers are available, which measure $\mathrm{NO}$ in a fast, noninvasive manner, and $\mathrm{FeNO}$ has been tested in the diagnosis and monitoring of asthma as well as for guiding treatment in schoolchildren and adults with asthma [5]. However, only a few studies have assessed the possible role of FeNO in wheezing preschool children or in preschool children at high risk of developing asthma.

In this issue of the European Respiratory Journal, CHANG et al. [6] showed that in infants and toddlers at high risk of developing asthma, prior to the first episode of wheezing, elevated FeNO was associated with a higher risk of asthma and increased airway reactivity at 5 years of age. This study differs from earlier studies on the predictive value of FeNO for asthma later in life as it included children from general paediatric practices before the first episode of wheezing and measured FeNO with an online single breath technique. The results were in line with earlier studies suggesting an association between FeNO early in life and respiratory symptoms, lung function, airways reactivity and/or asthma later in life [7-11]. The different populations studied, the different techniques used to measure FeNO and the different outcomes assessed may explain conflicting results with other studies [12-14]. CHAwEs et al. [12] showed that elevated 
FeNO at 1 month of age did precede transient early wheeze, but not persistent wheeze, and was unrelated to atopy.

One of the strengths of the study by CHANG et al. [6] is that it supports the concept that eosinophilic inflammation develops and increases in early childhood, and is a progressive phenomenon. Data from biopsy studies suggest that eosinophilic inflammation, which is a hallmark of asthma in school children, develops between 1 and 3 years of age $[15,16]$. By carrying out serial FeNO measurements between 1 and 5 years of age, or even from birth to school age, better insight into when eosinophilic inflammation starts could be obtained. CHANG et al. [6] suggest a gradual increase of FeNO during the study period, although this is somewhat speculative as only two measurements were available. It is well known that FeNO increases with age during childhood [17], and it is remarkable that FeNO does not seem to show this increase in the children who did not have asthma at 5 years of age. Longitudinal measurements are needed to gain more insight into this.

Another message from this study could be that measuring FeNO before 1 year of age for routine clinical care may be of little value, because at that age FeNO does not discriminate sufficiently between the various categories of patients, demonstrating too much overlap, as was observed by GABRIELE et al. [14].

Obviously, there is a signal in early FeNO measurements for predicting later development of asthma. However, does $\mathrm{FeNO}$ have an additive value over risk factors like aeroallergen sensitisation or a positive family history in prediction models for later asthma in preschool wheezing children? In the study by SINGER et al. [7] an asthma predictive index including elevated FeNO as a major criterion performed similarly to the classical asthma predictive index with blood eosinophilia as a minor criterion [18]. However, in the Dutch PIAMA (Prevention and Incidence of Asthma and Mite Allergy) cohort specific $\mathrm{IgE}$ and $\mathrm{FeNO}$ at 4 years both had an additive value over maternal allergy, eczema and frequency of wheeze in predicting the risk of asthma at 8 years of age [19].

Although in the study by SINGER et al. [7] the positive predictive value of the modified index could not be increased by FeNO, ELLIOTT et al. [9] recently showed that FeNO in children with a mean age of $\sim 15$ months with recurrent wheezing episodes had high positive and negative predictive values for wheezing and acute exacerbations at age 3 years, and also for a decline in lung function between 15 months and 3 years.

In the current study by CHANG et al. [6], FeNO was measured online with a constant expiratory flow during sedation, possibly resulting in minimal dilution with gas from the anatomical dead space and enhancing the sensitivity of the measurement. Although this technique makes comparison with standardised single breath online measurements at 5 years of age possible, only a few, specialised centres will have this technique available. Therefore, more effort should be put into online or offline techniques for which no cooperation and no specialised equipment is necessary, and which will be applicable for use in preschool children in general practice [20].

Prediction of school age asthma in high-risk preschool children may help to identify children who might need treatment with inhaled corticosteroids, who should be followed carefully and to whom future prevention strategies should be targeted. Obviously, FeNO measurements may be of help in identifying these children. However, more longitudinal data are needed, and easier, cheap and standardised techniques are needed to measure $F$ eNO in a way that is applicable in routine clinical care. Future perspectives in this field may include and combine other biomarkers in exhaled breath or exhaled breath condensate, or genetic markers [21].

\section{References}

1 Brand PL, Caudri D, Eber E, et al. Classification and pharmacological treatment of preschool wheezing: changes since 2008. Eur Respir J 2014; 43: 1172-1177.

2 Illi S, von Mutius E, Lau S, et al. Perennial allergen sensitisation early in life and chronic asthma in children: a birth cohort study. Lancet 2006; 368: 763-770.

3 Bisgaard H, Jensen SM, Bønnelykke K. Interaction between asthma and lung function growth in early life. Am J Respir Crit Care Med 2012; 185: 1183-1189.

4 Ducharme FM, Tse SM, Chauhan B. Diagnosis, management, and prognosis of preschool wheeze. Lancet 2014; 383: 1593-1604.

5 Pijnenburg MW, De Jongste JC. Exhaled nitric oxide in childhood asthma: a review. Clin Exp Allergy 2008; 38: 246-259.

6 Chang D, Yao W, Tiller CJ, et al. Exhaled nitric oxide during infancy as a risk factor for asthma and airway hyperreactivity. Eur Respir J 2015; 45: 98-106.

7 Singer F, Luchsinger I, Inci D, et al. Exhaled nitric oxide in symptomatic children at preschool age predicts later asthma. Allergy 2013; 68: 531-538.

8 Debley JS, Stamey DC, Cochrane ES, et al. Exhaled nitric oxide, lung function, and exacerbations in wheezy infants and toddlers. J Allergy Clin Immunol 2010; 125: 1228-1234.

9 Elliott M, Heltshe SL, Stamey DC, et al. Exhaled nitric oxide predicts persistence of wheezing, exacerbations, and decline in lung function in wheezy infants and toddlers. Clin Exp Allergy 2013; 43: 1351-1361. 
10 Kotaniemi-Syrjänen A, Malmberg LP, Malmström K, et al. Factors associated with elevated exhaled nitric oxide fraction in infants with recurrent respiratory symptoms. Eur Respir J 2013; 41: 189-194.

11 Latzin P, Kuehni CE, Baldwin DN, et al. Elevated exhaled nitric oxide in newborns of atopic mothers precedes respiratory symptoms. Am J Respir Crit Care Med 2006; 174: 1292-1298.

12 Chawes BL, Buchvald F, Bischoff AL, et al. Elevated exhaled nitric oxide in high-risk neonates precedes transient early but not persistent wheeze. Am J Respir Crit Care Med 2010; 182: 138-142.

13 Gabriele C, Jaddoe VW, van Mastrigt E, et al. Exhaled nitric oxide and the risk of wheezing in infancy: the Generation R study. Eur Respir J 2012; 39: 567-572.

14 Gabriele C, Nieuwhof EM, Van Der Wiel EC, et al. Exhaled nitric oxide differentiates airway diseases in the first two years of life. Pediatr Res 2006; 60: 461-465.

15 Saglani S, Payne DN, Zhu J, et al. Early detection of airway wall remodeling and eosinophilic inflammation in preschool wheezers. Am J Respir Crit Care Med 2007; 176: 858-864.

16 Saglani S, Malmström K, Pelkonen AS, et al. Airway remodeling and inflammation in symptomatic infants with reversible airflow obstruction. Am J Respir Crit Care Med 2005; 171: 722-727.

17 Buchvald F, Baraldi E, Carraro S, et al. Measurements of exhaled nitric oxide in healthy subjects age 4 to 17 years. J Allergy Clin Immunol 2005; 115: 1130-1136.

18 Castro-Rodríguez JA, Holberg CJ, Wright AL, et al. A clinical index to define risk of asthma in young children with recurrent wheezing. Am J Respir Crit Care Med 2000; 162: 1403-1406.

19 Caudri D, Wijga AH, Hoekstra MO, et al. Prediction of asthma in symptomatic preschool children using exhaled nitric oxide, Rint and specific IgE. Thorax 2010; 65: 801-807.

20 van Mastrigt E, de Groot RC, van Kesteren HW, et al. Tidal breathing FeNO measurements: a new algorithm. Pediatr Pulmonol 2014; 49: 15-20.

21 van der Schee MP, Hashimoto S, Schuurman AC, et al. Altered exhaled biomarker profiles in children during and after rhinovirus-induced wheeze. Eur Respir J 2014 [In press DOI: 10.1183/09031936.00044414]. 